\title{
Tomografía de Velocidad de Grupo de Ondas de Rayleigh para el Oriente de México y el Istmo de Tehuantepec
}

\author{
Francisco Córdoba Montiel ${ }^{1}$, Arturo Iglesias Mendoza ${ }^{2}$, Shri Krishna Singh ${ }^{2}$, Zack Spica ${ }^{2}$, \\ Denis Legrand ${ }^{2}$ \\ ${ }^{1}$ Centro de Ciencias de la Tierra de la Universidad Veracruzana, Francisco J. Moreno \# 207, Colonia Emiliano Zapata, C.P. 91000 ; \\ Xalapa, Veracruz. \\ ${ }^{2}$ Instituto de Geofísica de la UNAM, Circuito de la investigación Científica s/n, Ciudad Universitaria, Delegación Coyoacán, C.P. \\ 04510, México D.F.
}

*fcordobam72@gmail.com

\begin{abstract}
Resumen
En este trabajo se utilizaron registros de ruido sísmico de la red permanente de banda ancha del Servicio Sismológico Nacional de México y de las redes temporales de banda ancha MASE y VEOX para calcular las funciones de Green a partir de las correlaciones cruzadas de ruido de la componente vertical entre pares de estaciones. El arreglo MASE (Experimento de Subducción Mesoamericano) consistió en cien estaciones distribuidas a lo largo de un perfil perpendicular a la trinchera entre Acapulco, Guerrero, y Tempoal, Veracruz, cerca del Golfo de México. Este experimento operó de diciembre de 2004 a mayo de 2007. Cuarenta y seis de éstas estaciones se reubicaron en un perfil N-S va desde el Golfo de México hasta la costa del Pacífico, a través del Istmo de Tehuantepec. Este segundo arreglo de estaciones corrió de julio de 2007 a marzo de 2009 y se le denominó VEOX (Veracruz-Oaxaca). A partir de la función de Green extraída de la correlación cruzada entre cada par de estaciones, se obtuvieron las curvas de dispersión de ondas de Rayleigh, las cuales describen la velocidad de grupo promedio dentro de un intervalo de periodos determinado. Además, se utilizaron algunos sismos regionales registrados en estas redes sísmicas para obtener curvas de dispersión de ondas superficiales (Rayleigh) y, en consecuencia, la velocidad de grupo promedio entre cada par estación-epicentro. Este conjunto mezclado de mediciones de velocidad de grupo se invirtió para obtener imágenes tomográficas en periodos discretos (5-50 s). Las pruebas de resolución muestran que las regiones con mayor cobertura están en los alrededores de ambos experimentos temporales. Se obtiene un buen modelo de velocidad en un área grande entre ambos experimentos. En los periodos cortos $(<15 \mathrm{~s})$, las imágenes presentan buena correlación con las características geológicas superficiales. Las anomalías de baja velocidad están relacionadas con cuencas sedimentarias y áreas volcánicas del Cenozoico, mientras que las anomalías de altas velocidades se correlacionan con la región del antearco. Se observa una anomalía de baja velocidad muy clara al norte del Istmo de Tehuantepec, donde se encuentra un campo volcánico activo. En los periodos más grandes ( $>25 \mathrm{~s}$ ), una anomalía de baja velocidad coincide con la frontera de la Faja Volcánica Transmexicana, lo que sugiere la presencia de una cuña del manto. Para estos periodos, las anomalías de alta velocidad están relacionadas con la presencia superficial del manto oceánico en el antearco y de un manto menos profundo en el trasarco donde la corteza continental se adelgaza.
\end{abstract}

Palabras clave: Correlaciones-cruzadas, tomografía, curvas de dispersión, inversión, funciones de Green.

\begin{abstract}
In this study seismic noise records from the permanent broadband network of the Mexican National Seismological Service (Servicio Sismológico Nacional) and from the temporal broadband networks of MASE and VEOX have been used to compute the Green functions from vertical-vertical component of noise cross correlations between station pairs. MASE (Mesoamerican Seismic Experiment) consisted of one hundred stations deployed along a profile perpendicular to the trench from Acapulco, Guerrero, to Tempoal, Veracruz, Gulf of
\end{abstract}


Mexico. This experiment was carried out from December 2004 to May 2007. Forty six of these stations were relocated along a N-S profile crossing the Tehuantepec Isthmus from the Gulf of Mexico to the Pacific coast. These stations operated from July 2007 to March 2009 and this stage of the experiment was called VEOX (Veracruz-Oaxaca). From the Green functions extracted from the correlation for each pair of stations, Rayleigh wave dispersion curves were computed which represent the average group velocity between station pairs. Furthermore, regional earthquakes recorded by the stations were used in order to compute Rayleigh wave dispersion curves, which represent the average group velocity between epicenter-station pair. This mixed set of group velocity measurements was inverted to obtain tomographic images at discrete periods between 5 and $50 \mathrm{~s}$. Resolution tests show that the regions of best coverage surround both temporal experiments. A good velocity model was obtained in a large area between the two experiments. The images show good correlation at short periods $(<15 \mathrm{~s})$ with the shallowest geological features. Low velocity anomalies are related with sedimentary basins and Cenozoic volcanic areas, whereas high velocity anomalies correlate with the forearc region. A low-velocity anomaly was clearly observed at the north of the Isthmus of Tehuantepec where an active volcanic field is located. At larger periods (> $25 \mathrm{~s})$ a low velocity region coincides with the border of the Trans-Mexican Volcanic Belt, suggesting the presence of a mantle wedge. For these periods, high velocity anomalies are related with the shallow presence of the oceanic mantle in the forearc and the presence a shallower mantle in the backarc, where the continental crust becomes thin.

Keywords: Cross-correlations, tomography, dispersion curves, inversion, Green functions.

\section{Introducción}

Diversos estudios se han llevado a cabo con el fin de determinar la estructura de velocidades de la corteza y del manto superior bajo el territorio de México. Algunos de estos trabajos han propuesto modelos de velocidades obtenidos de ondas superficiales en áreas de gran escala (e.g., Fix, 1975; Gomberg et al., 1988, Van der Lee y Nolet, 1997; Vdovin et al., 1999). Otros trabajos se han centrado en proponer modelos regionales de velocidades para diversas zonas localizadas en el país (e.g., Valdés et al., 1986; Campillo et al., 1996; Iglesias et al., 2001).

México, como gran parte del mundo, se ha beneficiado de los avances en la tecnología de la instrumentación sísmica, del incremento en la densidad de estaciones permanentes desplegadas y de la contribución de redes sísmicas temporales que han permitido contar con nuevos modelos de velocidades cuya resolución es considerablemente mejor que antes. En este contexto, Iglesias et al. (2010) obtuvieron curvas de dispersión de velocidad de grupo de ondas de Rayleigh a partir de sismos regionales registrados en 18 estaciones de la red de banda ancha del Servicio Sismológico Nacional (SSN) y las 100 del experimento Mesoamerican Subduction Experiment (MASE, 2007). En ese trabajo los autores calcularon más de 1000 curvas de dispersión, pero debido a la geometría del arreglo MASE, la resolución fue limitada obteniendo información confiable solo para un perfil perpendicular a la Trinchera Mesoamericana.

Uno de los avances notables en la determinación de la estructura de la Tierra en años recientes, consistió en la propuesta de utilizar la correlación cruzada de registros continuos de ruido sísmico entre pares de estaciones y obtener una función equivalente a la función de Green del medio entre el par de estaciones (e.g., Lobkis y Weaver, 2001; Shapiro y Campillo, 2004). Esta función conserva la información contenida en las ondas superficiales viajando entre las dos estaciones y es posible extraer de ella, curvas de dispersión que conservan la información del medio de propagación entre el par de estaciones. Con un arreglo de estaciones sísmicas registrando simultáneamente, es posible obtener hasta $n ! /(n-2)$ ! curvas de dispersión donde $n$ es el número de estaciones. Si estas curvas de dispersión son invertidas con un esquema tomográfico, es posible encontrar mapas de velocidad o de perturbaciones de las mismas para la región abarcada por el arreglo. Esta técnica conocida genéricamente como Tomografía de Ruido Ambiental (ANT: Ambient Noise Tomography) ha sido extensamente utilizada en años recientes, para obtener características del medio de propagación a diferentes escalas (e.g., áreas tales como California (Shapiro et al., 2005), Europa (Yang et al., 2007)).

En el caso de México a escala regional, Gaite et al. (2012) calcularon mapas de velocidad de grupo y de fase para ondas de Rayleigh a partir de registros de ruido ambiental de estaciones localizadas en el Caribe, Estados Unidos, Centroamérica y México. Con este propósito, los autores obtuvieron $\sim 2500$ curvas de dispersión individuales correspondientes a pares de estaciones sísmicas, y usando el método propuesto por Barmin et al. (2001), determinaron mapas de velocidad de grupo y de fase para periodos entre los 8 y los $60 \mathrm{~s}$. Los autores de este trabajo reportan que la resolución alcanzada fue de hasta 250 x $250 \mathrm{~km}$ en las regiones con mejor cobertura de trayectorias interestaciones.

Con el fin de aumentar la resolución en la región centro, sur y este del territorio mexicano, en este trabajo se analizó un conjunto combinado de mediciones de dispersión obtenidas del método ANT y de sismos registrados por estaciones de los experimentos MASE, VEOX (VeracruzOaxaca; VEOX, 2010) y del SSN. Las pruebas de resolución muestran que con este conjunto combinado de datos es 
posible recuperar detalles en la estructura cortical de hasta $15 \times 15 \mathrm{~km}$.

\subsection{Marco Geológico y Tectónico}

Los trabajos pioneros de Campa y Coney (1983) propusieron que gran parte del territorio mexicano está constituido por un ensamble de masas corticales, con historias geológicas diferentes, que fueron acrecionadas a la placa de Norteamérica en distintos eventos tectónicos. Más tarde, los trabajos de Sedlock et al. (1993) y OrtegaGutiérrez et al. (1994) plantearon una subdivisión de México en terrenos tectonoestratigráficos siguiendo algunos de los lineamientos de Campa y Coney (1983). El resultado fue una subdivisión mucho más compleja que, sin embargo, se ha ido simplificando con la acumulación de nuevos fechamientos, datos estructurales y petrológicos en las zonas donde estos terrenos afloran en superficie, con la investigación de xenolitos acarreados por rocas volcánicas recientes y con la inspección de las rocas colectadas en perforaciones profundas (Gómez-Tuena et al., 2005). Cada uno de estos terrenos se caracteriza por una serie de unidades homogéneas y estratigráficamente continuas pero con relaciones entre sí poco comprendidas, que reposan sobre un basamento distinto, normalmente metamorfizado. En general los límites entre terrenos separan secuencias diferentes en sus caracteres físicos y temporales, y se han interpretado como límites tectónicos dado que no pueden ser claramente explicados por discordancias o cambios de facies convencionales. A su vez, dentro de los diferentes terrenos tectonoestratigráficos, las unidades se agrupan por lo general en conjuntos de unidades relacionadas entre sí denominados formaciones, o bien complejos si su origen es tectónico. Según este punto de vista, en la región de estudio se pueden distinguir, además de la Faja Volcánica Transmexicana (FVTM), seis terrenos tectonoestratigráficos (Figura 1): Terreno Guerrero, Terreno Mixteco, Terreno Cuicateco, Terreno Zapoteco, Terreno Maya y Terreno Chatino (Ortega-Gutiérrez et al., 2008).

En lo que respecta al sureste de México, a lo largo de la Sierra de Chiapas se encuentra una serie de bloques ascendentes y descendentes acotados por fallas laterales que definen lo que se conoce como la Provincia de Fallas Laterales (PFL), Figura 2. Esta provincia tiene alrededor de $350 \mathrm{~km}$ de largo por $100 \mathrm{~km}$ de ancho; en su parte oriental se observa que la mayoría de las fallas transcurrentes tienen un rumbo este-oeste, mientras que hacia el oeste tiene un rumbo de $\mathrm{N} 50^{\circ} \mathrm{W}$ (Meneses-Rocha, 1985). Al oriente de la Sierra Madre de Chiapas y en la parte norte-central de Guatemala se encuentra la Provincia de Fallas Inversas (PFI). Está formada por anticlinales largos y angostos, truncados en sus flancos por fallas inversas que impiden visualizar el correspondiente sinclinal (Guzmán-Speziale y Meneses-Rocha, 2000). En esta zona afloran carbonatos del Cretácico Tardío en las crestas, mientras que rocas de origen terrígeno y de edades desde el Paleógeno hasta el Mioceno cubren la superficie de los sinclinales, apuntando a que el plegamiento y fallamiento sucedieron hacia el Mioceno, lo que es similar a la edad sugerida para el fallamiento de la Provincia de Fallas Laterales.

Por medio de datos estructurales combinados con el análisis de imágenes satelitales y perfiles sísmicos,

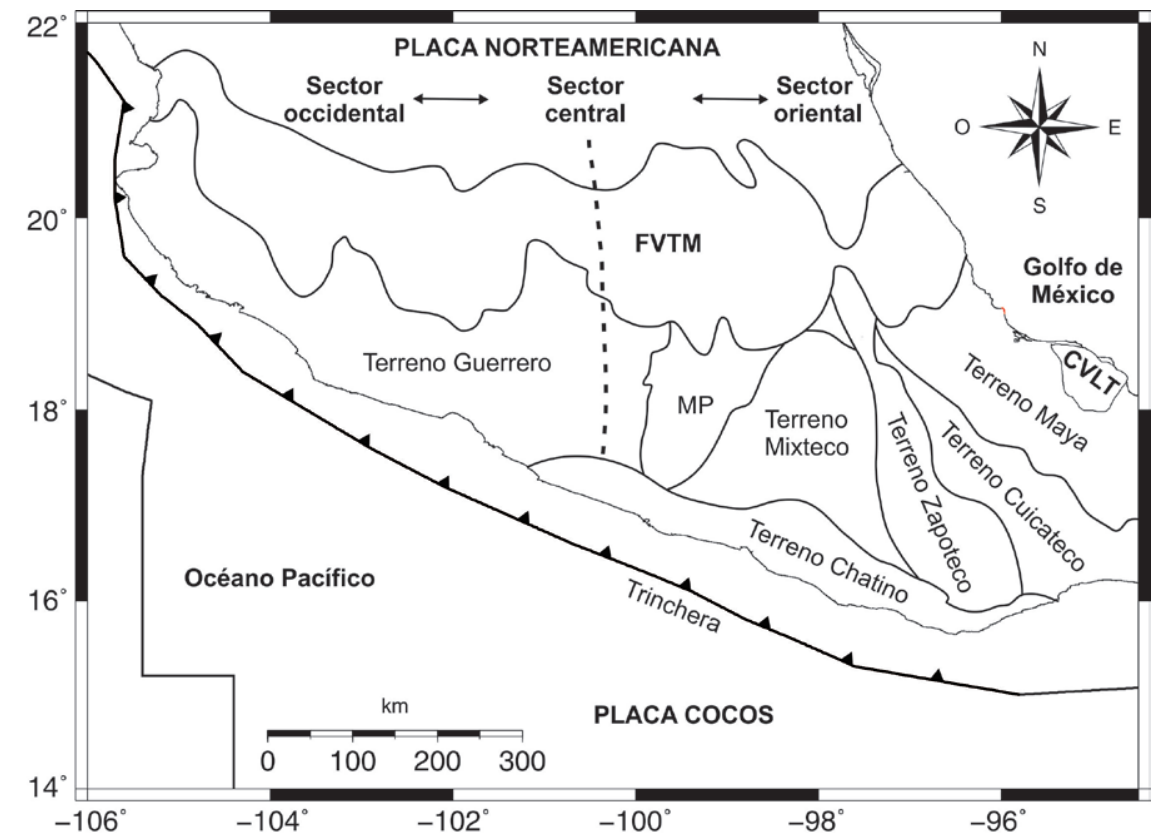

Figura 1. Terrenos tectonoestratigráficos de la zona centro-sur de México. Se añade la Plataforma de Morelos (MP) como una posible nueva unidad tectoestratigráfica con basamento distinto metamorfizado en muy alto grado (Modificada de Ortega-Gutiérrez et al., 2008), la Faja Volcánica Transmexicana (FVTM) y el Campo Volcánico Los Tuxtlas (CVLT). 


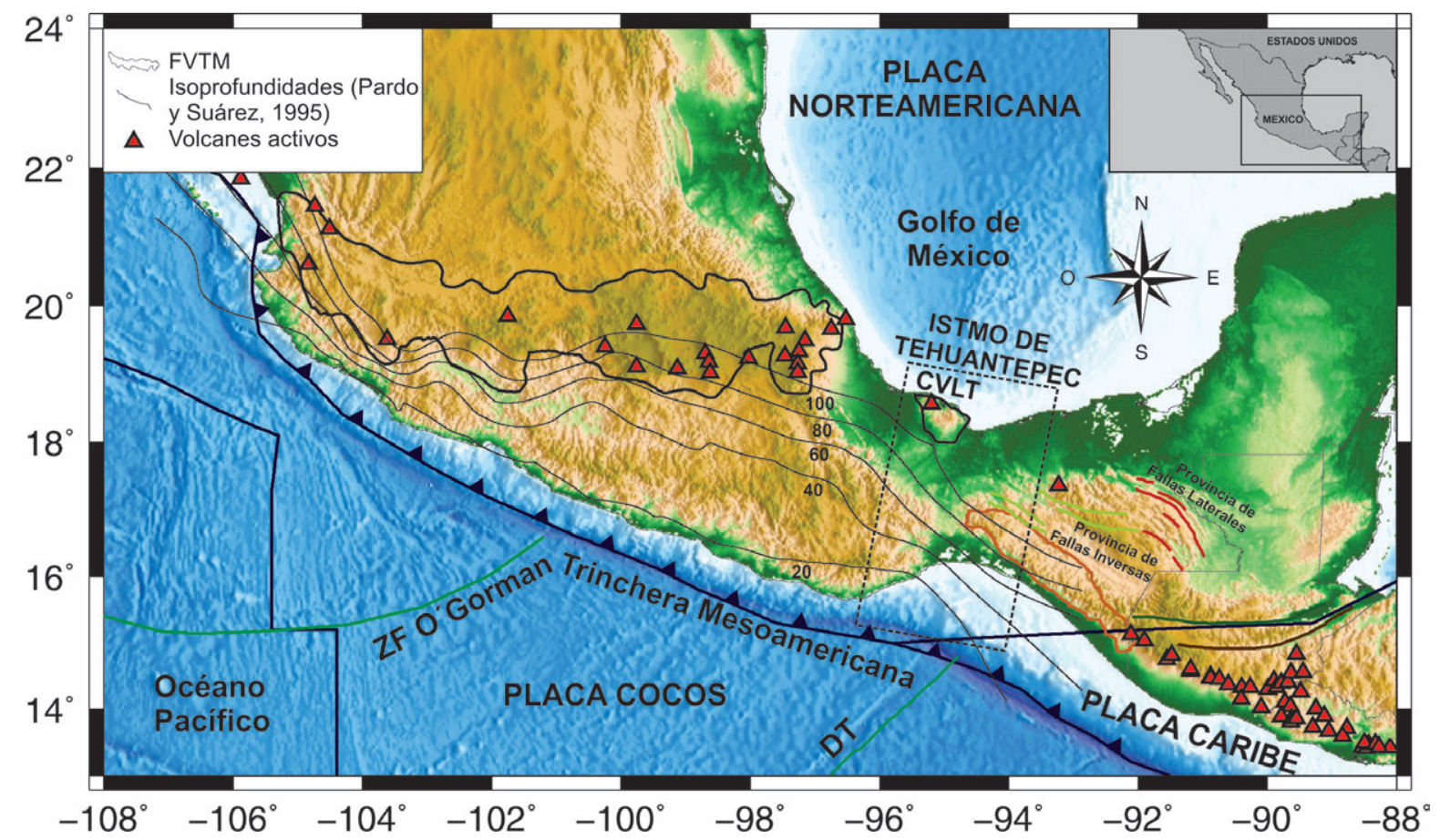

Figura 2. Principales características tectónicas de la región entre las que se que incluye a la Faja Volcánica Transmexicana (FVTM), Campo Volcánico de Los Tuxtlas (CVLT), provincias de fallas en la región (Guzmán-Speziale y Meneses-Rocha, 2000), Zona de Fractura (ZF) de O'Gorman, Dorsal de Tehuantepec (DT), así como las curvas de isoprofundidades determinadas por Pardo y Suárez (1995).

Andreani et al. (2008) encontraron evidencias de un deslizamiento lateral-izquierdo a lo largo del bloque del sur de México. Esta falla afecta a la cuenca de Veracruz y se extiende hasta el Campo Volcánico de Los Tuxtlas (CVLT), que es el principal alineamiento volcánico que se ubica a lo largo de esta falla.

Recientemente, Kim et al. (2011) han propuesto la existencia de una placa subducida que buza hacia el suroeste de México. Su argumento principal surge de una imagen de funciones receptor obtenida con registros telesísmicos de estaciones del experimento VEOX a través del Istmo de Tehuantepec y también soportado por un modelo tomográfico previo (Li et al., 2008). Esta placa subducida buza a $35^{\circ}$, tiene aproximadamente $250 \mathrm{~km}$ de longitud y parece truncar a la de Cocos aproximadamente a una profundidad de $120 \mathrm{~km}$. La hipótesis que plantean para explicar el fenómeno, es que esta placa se creó de la subducción de litosfera oceánica previa a la colisión del Bloque de Yucatán con México, hace aproximadamente 12 Ma. Este escenario explicaría el Plegamiento de Chiapas y el Cinturón de fallas inversas como producto de esta colisión. En la Figura 2 se presenta un mapa tectónico que comprende la región de estudio del presente trabajo.

\section{Datos}

Los datos utilizados en el presente estudio se obtuvieron de los arreglos sísmicos temporales de banda ancha
MASE y VEOX, además de contar con los aportados por estaciones de la red permanente de banda ancha del Servicio Sismológico Nacional (SSN).

El Experimento de Subducción de Meso-América en México tuvo el objetivo de modelar el comportamiento dinámico de la placa de Cocos debajo de la de Norteamérica, y consistió en la instalación de dos arreglos temporales de estaciones sísmicas de banda ancha en diferentes periodos. El primero de ellos conocido como arreglo MASE, estuvo conformado por 100 estaciones a lo largo de una línea de 600 km que partió desde Acapulco, Guerrero en el Pacífico hasta Tempoal, Veracruz, cerca del Golfo de México, pasando por la Ciudad de México. La operación de estas estaciones inició en diciembre de 2004 y concluyó en mayo de 2007.

La segunda etapa del experimento (julio de 2007 - marzo de 2009) denominada VEOX, (Veracruz-Oaxaca) estuvo conformada por 46 estaciones temporales que se instalaron a lo largo de un perfil de $300 \mathrm{~km}$ de longitud, ubicado entre San Mateo del Mar, Oaxaca en la costa del Pacífico y Monte Pío, Veracruz en la costa del Golfo de México (Figura 3). De la red sísmica permanente de banda ancha del Servicio Sismológico Nacional, se utilizaron los datos de estaciones ubicadas en los estados de Veracruz, Oaxaca, Chiapas, Puebla, Hidalgo, Morelos, Guerrero y la Ciudad de México.

Los datos de ruido sísmico continuo y de terremotos registrados en cada una de las redes antes mencionadas dieron lugar a cuatro grupos que fueron utilizados para obtener inversiones tomográficas para diferentes periodos, donde cada uno de ellos se procesó de la siguiente forma: 


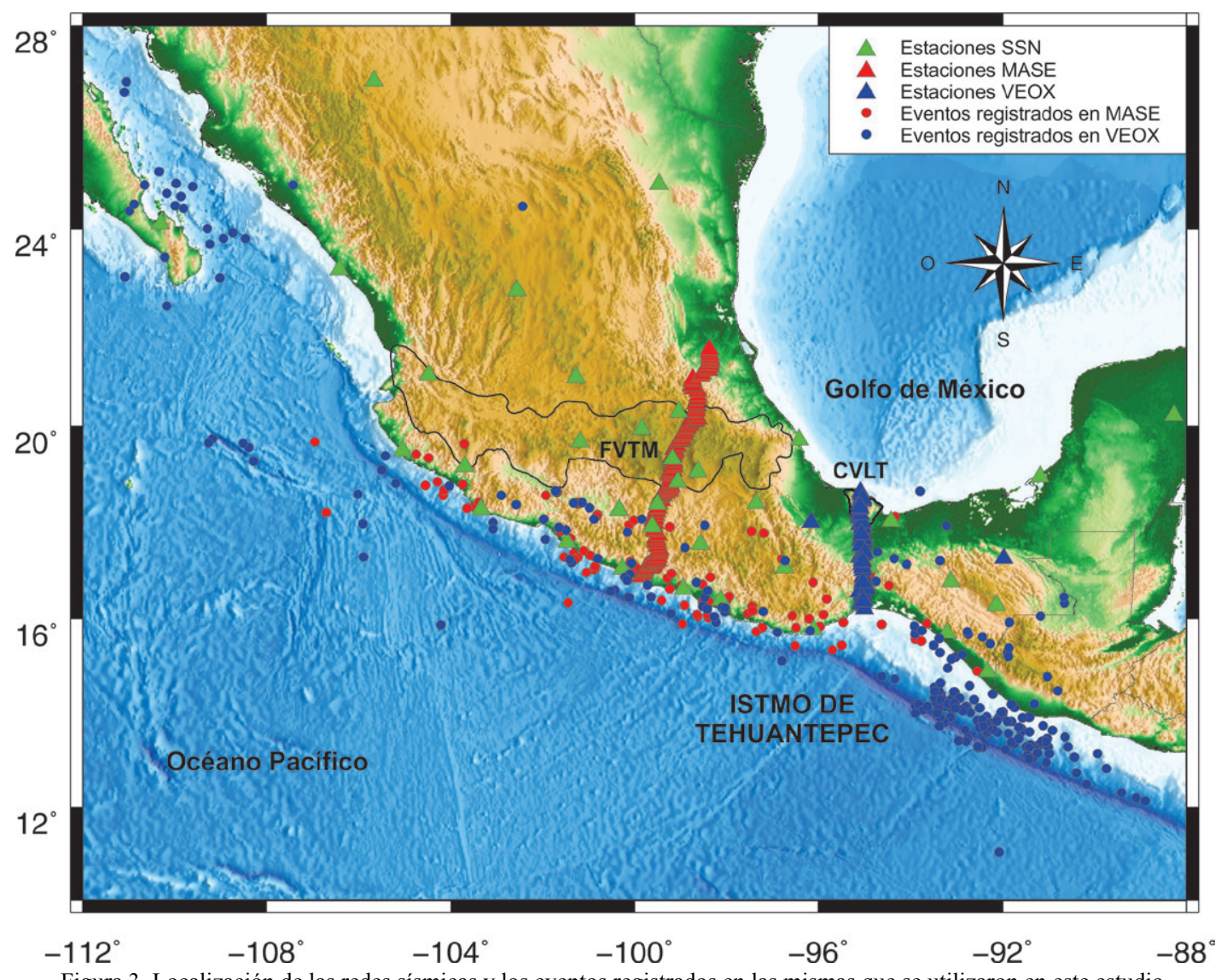

Figura 3. Localización de las redes sísmicas y los eventos registrados en las mismas que se utilizaron en este estudio.

I. En el cálculo de las curvas de dispersión de ondas superficiales, utilizando correlaciones cruzadas de ruido sísmico entre pares de estaciones, se emplearon los datos de VEOX y del SSN correspondientes al lapso de tiempo en que el arreglo VEOX se mantuvo en operación.

II. El segundo bloque de datos correspondió a las curvas de dispersión que fueron calculadas entre el arreglo MASE y algunas estaciones del SSN a partir de registros de ruido sísmico.

III. A lo antes mencionado, se agregaron las curvas de dispersión obtenidas por Iglesias et al. (2010) a partir de 90 eventos regionales con $\mathrm{M} \geq 4.5$ que fueron registrados por estaciones del arreglo MASE y del SSN y relocalizados con un RMS $<0.5 \mathrm{~s}$. Las velocidades de grupo del modo fundamental de ondas de Rayleigh se midieron utilizando la componente vertical de los sismogramas utilizados.

IV. Con la finalidad de mejorar la resolución de la inversión tomográfica mediante el incremento del número de trayectorias y constituyendo una cuarta fuente de datos, se utilizaron los sismogramas de 230 eventos con $\mathrm{M}$ $\geq 4.5$ que fueron reportados por el SSN y registrados en el arreglo VEOX y algunas estaciones del SSN. De forma similar al trabajo de Iglesias et al. (2010), se calcularon las curvas de dispersión para obtener la velocidad de grupo promedio entre cada par estaciónevento.

La Figura 3 muestra un mapa con las localización de las estaciones sísmicas de banda ancha que fueron utilizadas para la obtención de las curvas de dispersión usando datos de ruido sísmico y eventos, los sismos registrados en el arreglo MASE de acuerdo con el trabajo de Iglesias et al. (2010) y los registrados por el arreglo VEOX.

\section{Método}

La tomografía sísmica de la velocidad de grupo de ondas superficiales, se calculó a través de la técnica de regionalización continua propuesta por Debayle y Sambridge (2004) e incluyó los conjuntos de datos antes mencionados. Las pruebas de consistencia a través de diagramas de Voronoi mostraron una buena resolución en el área de interés. Alternativamente, con el objeto de corroborar los resultados obtenidos, se realizó una segunda tomografía utilizando la metodología presentada por Rawlinson y Sambridge (2003) que se basa en la tomografía sísmica de tiempos de viaje a través del método denominado Fast Marching Surface Tomography. 
Un enfoque clásico en la tomografía de ondas superficiales es construir un modelo tridimensional (3-D) de velocidades sísmicas en dos etapas. La primera involucra una regionalización en 2-D y la segunda una inversión para profundidad. El paso de regionalización se realiza en 2-D debido a que los parámetros sísmicos locales se recuperan de un conjunto de mediciones de "velocidad promedio" entre el epicentro y una estación cuando se utilizan registros de eventos o pares de estaciones en el caso de ruido sísmico. Los mapas de velocidad de fase o de grupo, se construyen para diferentes periodos y después se aplican métodos de inversión para producir modelos de velocidad de ondas S contra profundidad (e.g. Ritzwoller et al., 2001) completamente en 3-D. Cabe mencionar que en este trabajo se presenta la regionalización en 2-D para la zona de interés, obteniéndose como resultado una variedad de mapas tomográficos con alta resolución para distintos periodos.

3.1. Funciones de Green de correlaciones cruzadas de ruido sísmico

Las funciones de Green pueden extraerse a partir de correlaciones cruzadas de ruido sísmico como se ha demostrado desde diferentes enfoques por Lobkis y Weaver (2001), Derode et al. (2003), Wapenaar (2004), Snieder (2004), Roux et al. (2005), Wapenaar et al. (2006), Snieder et al. (2007), entre otros. En el campo de la sismología en general se encuentra una diversidad de aplicaciones tales como: heliosismología (Duvall et al., 1993; Ricket y Claerbout, 1999, 2000), monitoreo de fallas y volcanes (Sens-Schönfelder y Wegler, 2006; Wegler y SensSchönfelder, 2007; Brenguier et al., 2008), sismología de exploración (Schuster et al., 2004; Bakulin y Calvert, 2006), sismología cortical (Campillo y Paul, 2003; Shapiro y Campillo, 2004; Shapiro et al., 2005; Sabra et al., 2005) y sismología global (Nishida et al., 2009, Poli et al., 2012).

Teóricamente es posible demostrar que la función de Green del medio elástico entre un par de estaciones, es proporcional a la derivada temporal de la correlación cruzada de ruido sísmico, siempre y cuando el ruido sísmico sea considerado un campo difuso. Una manera de satisfacer esa condición es que las fuentes de ruido estén igualmente distribuidas alrededor del par de estaciones. En la práctica, sin embargo, esta condición no se cumple para la mayoría de estudios de ruido sísmico ambiental dado que las fuentes del ruido sísmico tienen posiciones definidas (como en el caso del oleaje marino) o son más energéticas que otras fuentes de ruido (como en el caso del ruido de origen antrópico). Otra forma, es tener un medio altamente heterogéneo. En el caso de México, la distribución no homogénea de las fuentes de ruido puede ser compensada por la alta heterogeneidad del medio de propagación.

Para superar este problema se ha propuesto usar el promedio de las correlaciones cruzadas para periodos de tiempo largos (e.g. Shapiro y Campillo, 2004), del orden de 30 meses para MASE y 20 meses para VEOX.

3.2. Medición de la velocidad de grupo de ondas de Rayleigh en datos de ruido sísmico

La metodología que se utilizó para el procesamiento de datos de ruido ambiental y la obtención de curvas de dispersión de ondas superficiales consistió en cuatro etapas principales de acuerdo con Bensen et al. (2007), las cuales se describen brevemente a continuación:

\subsubsection{Preparación de datos de estaciones individuales}

La primera fase del procesamiento consistió en la preparación de los datos de las series de tiempo de cada estación individualmente. En esta etapa, que constituye la fase 1 de la Figura 4, se recopilaron las series de tiempo de los datos disponibles que coinciden en las diferentes redes, es decir, combinaciones entre pares de estaciones de MASE y SSN por un lado y de VEOX y del SSN por otro lado. Cabe mencionar que las redes MASE y VEOX no coincidieron temporalmente. Las series de tiempo que se utilizaron de cada estación (datos crudos) se recortaron para tener una duración de 24 horas a una tasa de $1 \mathrm{mps}$ (muestra/segundo). Para cada registro de ruido sísmico, con estas características, fue necesario remover la media y la tendencia, así como respuesta instrumental. Se aplicó un filtrado pasabanda entre 5 y $50 \mathrm{~s}$, que es la banda de frecuencias de interés para el cálculo de la tomografía. Posteriormente, se llevó a cabo la normalización temporal (normalización en el dominio del tiempo o temporización normal), que es un procedimiento para reducir el efecto de los sismos sobre las correlaciones cruzadas, irregularidades instrumentales y las fuentes de ruido no estacionarias cercanas a las estaciones. Los sismos se encuentran entre los impedimentos más significativos para realizar el procesamiento automático de los datos debido a que ocurren irregularmente y aunque los tiempos aproximados y las localizaciones de los grandes sismos pueden encontrarse en los catálogos de sismos, los temblores pequeños en gran parte del mundo no se encuentran en los catálogos globales. Además, el tiempo de arribo de las fases correspondientes a las ondas de superficie en los periodos cortos no es bien conocido. En consecuencia, el hecho de remover los sismos de los registros debe ser un proceso adaptativo a los datos, más que prescritos a un catálogo. En este trabajo seguimos el procedimiento de normalización temporal propuesto por Bensen et al. (2007).

Es bien conocido que el espectro de ruido ambiental presenta picos en periodos relativamente bien definidos (Peterson, 1993). Un ejemplo de estos picos se localiza alrededor de $6 \mathrm{~s}$ y corresponde al periodo del oleaje en las costas. Esta distribución heterogénea de la energía del ruido ambiental provoca que las curvas de dispersión solo estén bien definidas para los períodos dónde se distribuyen estos picos. Con efecto de recuperar mayor información en las curvas de dispersión, en este trabajo se sigue el procedimiento propuesto por Bensen et al. (2007) y que 
consiste en calcular el espectro de la señal, dividirla entre el espectro suavizado y regresar la señal al dominio del tiempo.

\subsubsection{Correlaciones cruzadas y apilamiento temporal}

Aunque algunas distancias entre estaciones pueden ser demasiado cortas o demasiado largas para obtener mediciones confiables, se calcularon las correlaciones cruzadas entre todos los pares de estaciones disponibles y posteriormente se llevó a cabo su apilado como se señala en la fase 2 de la Figura 4. La diversidad de estaciones sísmicas dio lugar a las siguientes combinaciones posibles: MASE-SSN, MASE-MASE, VEOX-SSN, VEOX-VEOX y SSN-SSN.

Además de las correlaciones, el apilamiento de los correlogramas cruzados es de suma importancia para mejorar adicionalmente la emergencia de señales a través de su apariencia coherente. Para el apilado temporal se utilizó el método propuesto por Schimmel et al. (2010), quienes emplearon el apilamiento ponderado en fase en el dominio tiempo-frecuencia (tf-PWS) propuesto por Schimmel y Gallart (2007). La estrategia tf-PWS también ha sido utilizada por Baig et al. (2009) en la eliminación del ruido de correlogramas cruzados de ruido para una extracción más eficiente de ondas de Rayleigh y Love.

\subsubsection{Medición de curvas de dispersión}

Las curvas de dispersión se obtuvieron a través de la técnica de filtrado múltiple (Dziewonski et al., 1969) que consiste en la aplicación de un conjunto de filtros de amplitud Gaussiana con diferentes frecuencias centrales para la entrada del espectro, seguidos por el cálculo de la transformada de Fourier inversa. Esta técnica es un método rápido y eficiente para el análisis de señales dispersadas múltiples. Las amplitudes y fases de las señales que pasan por un arreglo de filtros de banda estrecha pueden utilizarse para medir velocidad de grupo, excitación relativa y transmisión como funciones del periodo y la velocidad, refracción lateral, vibraciones modales de la superficie, y otros parámetros de dispersión asociados con una variedad de modos registrados por una estación individual para un evento. La Figura 5 ilustra algunas de las curvas de dispersión obtenidas con datos de ruido sísmico, mientras que la Figura 6 presenta un mapa con la ubicación de los pares de estaciones y las trayectorias que se emplearon para calcular dichas curvas.

Los tiempos de arribo de grupo se estiman de los máximos de las envolventes de tiempo. Es sabido que este método conduce a un error sistemático en las mediciones de velocidad de grupo (Levshin et al., 1989) debido a la asignación errónea de la frecuencia relacionada con la variación de la amplitud espectral, la cual desplaza la frecuencia central del espectro filtrado. Para eliminar este error, se aplica la corrección propuesta por Shapiro y Singh (1999) en la asignación de la frecuencia de cada valor de velocidad de grupo. Esta solución consiste en el cálculo de una frecuencia centroide, en la que el espectro filtrado alcanza su máximo. El espectro filtrado se asigna a esta frecuencia centroide.

\subsubsection{Selección de curvas de dispersión.}

Cada curva de dispersión se sometió a un proceso de selección individualizado en el que se les comparó con dos curvas de referencia obtenidas por Iglesias et al., 2001. Los intervalos de los periodos en los cuales las curvas obtenidas fueron inconsistentes con las de referencia fueron descartados.

\subsection{Inversión tomográfica utilizando un algoritmo de regionalización continua}

La inversión tomográfica se realizó para diferentes periodos utilizando el algoritmo de regionalización continua propuesto por Debayle y Sambridge (2004), para invertir el conjunto de velocidades de grupo de cada periodo. Este algoritmo utiliza una formulación continua del problema inverso y un criterio de mínimos cuadrados. Una función de covarianza Gaussiana a priori controla el grado de suavizado horizontal en el modelo invertido. Debayle y Sambridge (2004) enfocan su trabajo en el paso de regionalización 2-D y siguen el formalismo de Tarantola y Valette (1982)

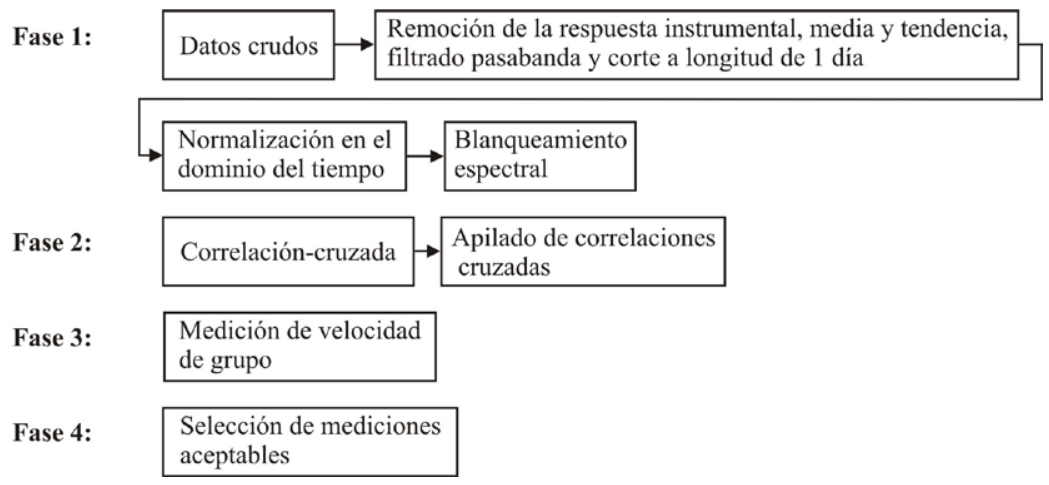

Figura 4. Representación esquemática del procesamiento de datos de ruido sísmico. La fase 1 contiene los pasos involucrados en la preparación individual de los datos. La fase 2 corresponde a las correlaciones cruzadas entre pares de estaciones y su apilado. Las fases 3 y 4 contemplan el cálculo de curvas de dispersión y su selección (Modificado de Bensen et al., 2007). 

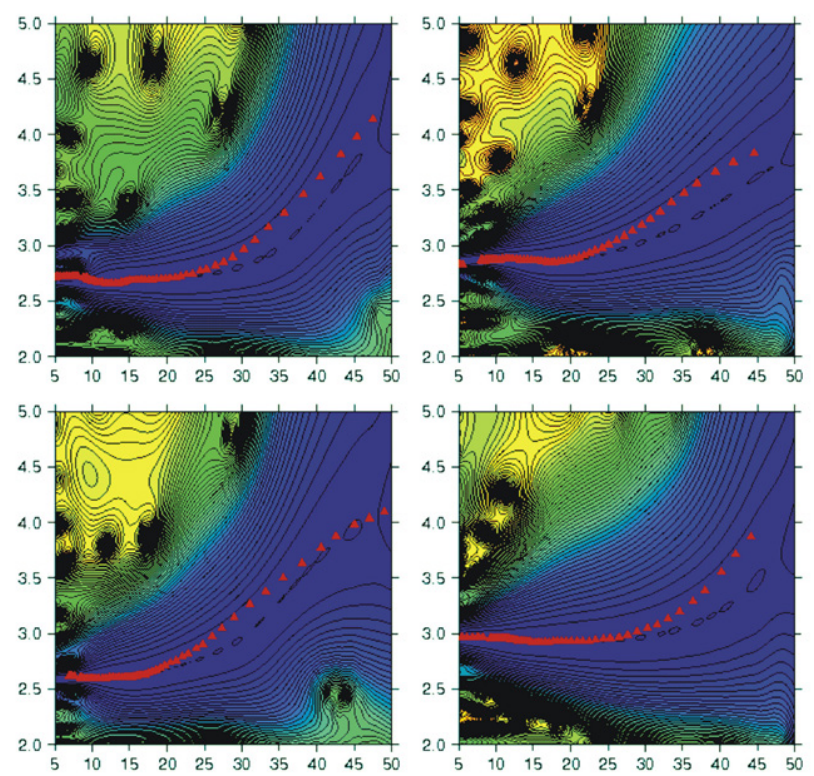

Figura 5. Ejemplos de curvas de dispersión de la velocidad de grupo obtenidas a través de la técnica de filtrado múltiple (Dziewonski et al., 1969), que se calcularon a partir correlaciones cruzadas de ruido sísmico entre pares de estaciones del arreglo VEOX y algunas estaciones de la red del SSN de México. Siendo el eje horinzontal de "Periodo(s)" y el vertical de "Velocidad de Grupo (km/s)". para un problema inverso de mínimos cuadrados donde las incógnitas son una función de una variable continua y en donde la relación teórica entre los datos y las incógnitas se supone que es lineal. Este formalismo ha sido aplicado a ondas de cuerpo por Tarantola y Nercessian (1984) y a ondas de superficie por Montagner (1986). La Tabla 1 contiene el listado de la velocidad de grupo promedio de algunos de los periodos utilizados en este trabajo y el número de trayectorias empleado en cada uno de ellos. En la Figura 7 se presentan las imágenes tomográficas como perturbación del modelo de referencia para los periodos desde $\mathrm{T}=5 \mathrm{~s}$ hasta $\mathrm{T}=50 \mathrm{~s}$ en incrementos de $5 \mathrm{~s}$.

En nuestro problema, la región se discretizó inicialmente como una malla regular de $1 / 8^{\circ} \times 1 / 8^{\circ}$. Se eligió como modelo inicial el determinado por Iglesias et al. (2001) para trayectorias perpendiculares a la costa del Pacífico y se realizó una inversión tomográfica por separado para cada periodo.

\subsubsection{Pruebas de resolución a través de Diagramas de Voronoi}

Debayle y Sambridge (2004) propusieron un procedimiento para estimar la variación de restricción proporcionada por la cobertura de la trayectoria del

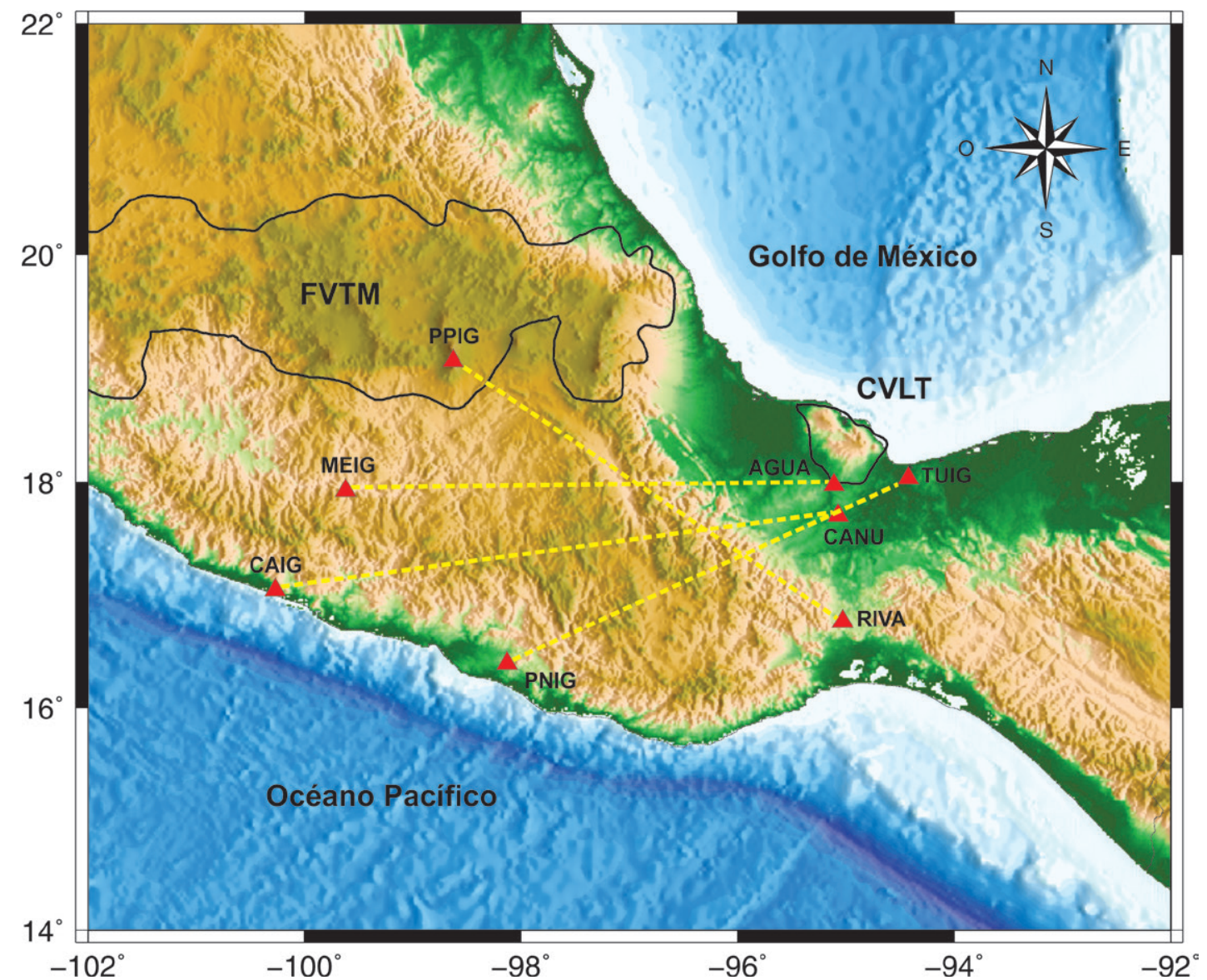

Figura 6. Mapa de las trayectorias correspondientes a los pares de estaciones cuyas curvas de dispersión fueron obtenidas a partir de correlaciones cruzadas de ruido sísmico y que se muestran en la Figura 5. 
Tabla 1. Valores de velocidad de grupo y número de trayectorias válidas para algunos periodos utilizados en el cálculo de la inversión tomográfica a través del método de Debayle y Sambridge (2004).

\begin{tabular}{ccc}
\hline $\mathbf{T}(\mathbf{s})$ & $\mathbf{U}(\mathbf{k m} / \mathbf{s})$ & Trayectorias $(\#)$ \\
\hline 5 & 2.8318 & 349 \\
6 & 2.8189 & 1289 \\
7 & 2.8072 & 1717 \\
8 & 2.8026 & 1930 \\
9 & 2.8016 & 2058 \\
10 & 2.8073 & 2206 \\
15 & 2.8881 & 2620 \\
20 & 2.9452 & 2990 \\
25 & 3.1028 & 3274 \\
30 & 3.5468 & 1116 \\
35 & 3.6919 & 1176 \\
40 & 3.8817 & 904 \\
45 & 3.8817 & 650 \\
50 & 3.9345 & 366 \\
\hline
\end{tabular}

rayo. Este enfoque hace uso de técnicas de geometría computacionales, las cuales se han visto en tiempos recientes en varias aplicaciones a problemas geofísicos. Sambridge et al. (1995) presentaron una técnica para interpolar una propiedad de la Tierra especificada en una serie de puntos de referencia, mientras que Gudmundsson y Sambridge (1998) y Sambridge y Faletič (2003) hicieron uso de poliedros Voronoi y tetraedros Delaunay como una parametrización para tomografía de tiempos de viaje en 3-D. En todos los casos, los algoritmos del campo de la geometría computacional se utilizan para dividir un medio en triángulos Delaunay (tetraedro en tres dimensiones) o celdas Voronoi (poliedro en tres dimensiones) construidos alrededor de un conjunto de nodos de referencia espaciados irregularmente. En dos dimensiones, un diagrama de Voronoi divide el plano en un conjunto de polígonos, uno aproximadamente por cada nodo, de tal forma que todos los puntos en una celda en particular están más cerca del nodo que los define que de cualquier otro nodo. El cálculo de los diagramas de Voronoi es un proceso iterativo en el que se van borrando los vértices de los nodos hasta que se cumple con un criterio de acuerdo al número de trayectorias y cobertura azimutal de los mismos.

Siguiendo la metodología propuesta por Debayle y Sambridge (2004), las pruebas de resolución de las inversiones tomográficas se realizaron por medio de diagramas de Voronoi. La Figura 8 incluye los diagramas resultantes calculados para cuatro periodos particulares con sus respectivos mapas de trayectorias: (a) $\mathrm{T}=10 \mathrm{~s}$, (b) $\mathrm{T}=$ $15 \mathrm{~s}$, (c) $\mathrm{T}=20 \mathrm{y}$ (d) $\mathrm{T}=25 \mathrm{~s}$.

3.4. Inversión tomográfica de tiempos de viaje calculadas con The Fast Marching Method

Con el propósito de verificar los resultados obtenidos en la inversión tomográfica realizada mediante al algoritmo de regionalización continua, se utilizó el método propuesto por Rawlinson y Sambridge (2005), denominado Fast Marching Method (FMM). Esta técnica tomográfica 2-D iterativa no lineal permite obtener mapas de velocidad de ondas de Rayleigh y presenta la ventaja de ofrecer soluciones estables y robustas en medios altamente heterogéneos (Rawlinson y Sambridge, 2004; de Kool et al., 2006). En cada iteración la trayectoria de rayo entre las estaciones se actualiza de tal forma que se toma en cuenta la longitud de las trayectorias. Dentro del proceso de inversión, se realiza la perturbación de los modelos del parámetro para que coincida con la medición de velocidad de grupo operando una linealización local en el modelo actual. Una vez que se estima la perturbación del modelo, se actualiza el modelo y se vuelven a trazar las trayectorias de propagación usando el esquema FMM.

Los cuatro bloques de datos antes descritos fueron procesados para adaptarlos a los requerimientos de entrada del paquete FMST desarrollado por Rawlinson. En la Tabla 2 se desglosan algunas velocidades de grupo y el número de trayectorias empleadas para su determinación y en la Figura 9 se presentan las inversiones tomográficas para algunos periodos utilizando este método.

En la Figura 10, se grafica un histograma mostrando la distribución de los desajustes para el modelo inicial (a) y para el modelo final (b) para $\mathrm{T}=30 \mathrm{~s}$. En lo que respecta a las pruebas de resolución realizadas para evaluar los resultados de esta técnica, se hicieron pruebas de sensibilidad de tablero de ajedrez, las cuales son útiles para evaluar la capacidad de la inversión tomográfica de resolver detalles estructurales en la Tierra. La Figura 11 muestra los tableros de ajedrez del modelo recuperado para cuatro periodos distintos.

\section{Discusión}

En esta sección analizamos los resultados de la tomografía sísmica con la finalidad de correlacionarlos con las principales características geológicas y tectónicas del área de estudio. El objetivo de realizar la inversión tomográfica del mismo conjunto de datos a través de dos técnicas diferentes fue corroborar la congruencia de los resultados obtenidos, tomando en cuenta que la cantidad de datos involucrados permitió obtener imágenes tomográficas con una resolución sin precedentes.

Los periodos cortos (menores a $15 \mathrm{~s}$ ) están asociados a las características más superficiales de las estructuras geológicas. En general, las anomalías de baja velocidad muestran una correspondencia con cuencas sedimentarias, mientras que las de alta velocidad están asociadas con los principales rasgos fisiográficos tales como la Sierra Madre Oriental y la Sierra Madre del Sur (e.g., Gaite et al., 2012). Los mapas tomográficos de velocidad de grupo obtenidos presentan una buena correlación con las estructuras geológicas más prominentes de la región de estudio. La principal anomalía de baja velocidad que se observa en 

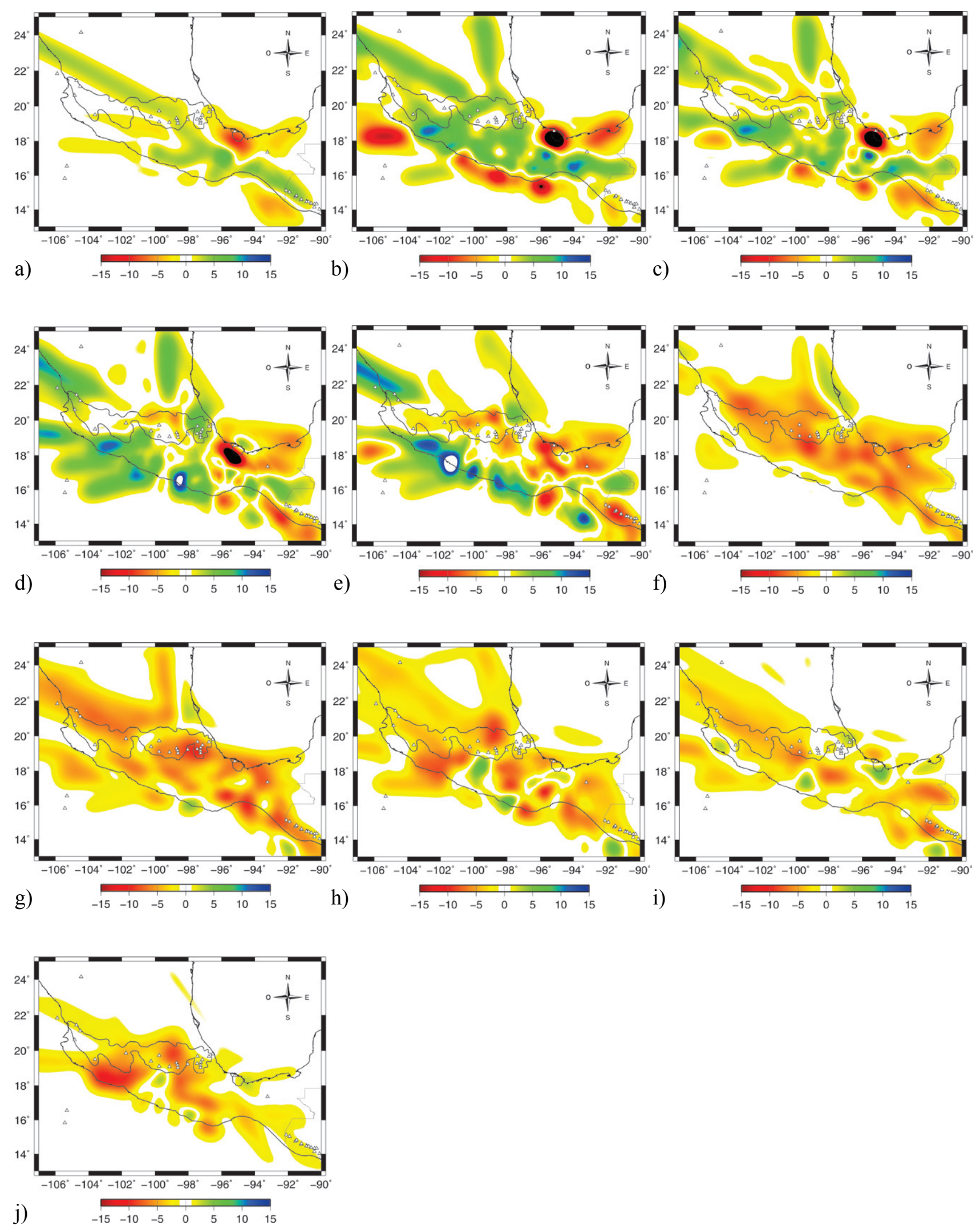

Figura 7. Imágenes tomográficas de alta resolución de ondas superficiales para diferentes periodos calculadas mediante la técnica propuesta por Debayle y Sambridge (2004) y en las que se emplearon correlaciones cruzadas de ruido sísmico y eventos registrados en las estaciones utilizadas en este estudio. La escala de colores representa la variación en unidades de porcentaje de la velocidad de grupo con respecto al modelo de referencia. Los triángulos blancos indican la ubicación de los volcanes de la región y los contornos, las áreas de la FVTM y el CVLT. Los mapas tomográficos corresponden a los periodos: a) $\mathrm{T}=5 \mathrm{~s}$, b) $\mathrm{T}=10 \mathrm{~s}$, c) $\mathrm{T}=15 \mathrm{~s}$, d) $\mathrm{T}=20 \mathrm{~s}$, e) $\mathrm{T}=25 \mathrm{~s}, \mathrm{f}) \mathrm{T}=30 \mathrm{~s}, \mathrm{~g}$ ) $\mathrm{T}=35 \mathrm{~s}, \mathrm{~h}) \mathrm{T}=40 \mathrm{~s}$, i) $\mathrm{T}=45 \mathrm{~s} \mathrm{y} \mathrm{j}) \mathrm{T}=50 \mathrm{~s}$. 

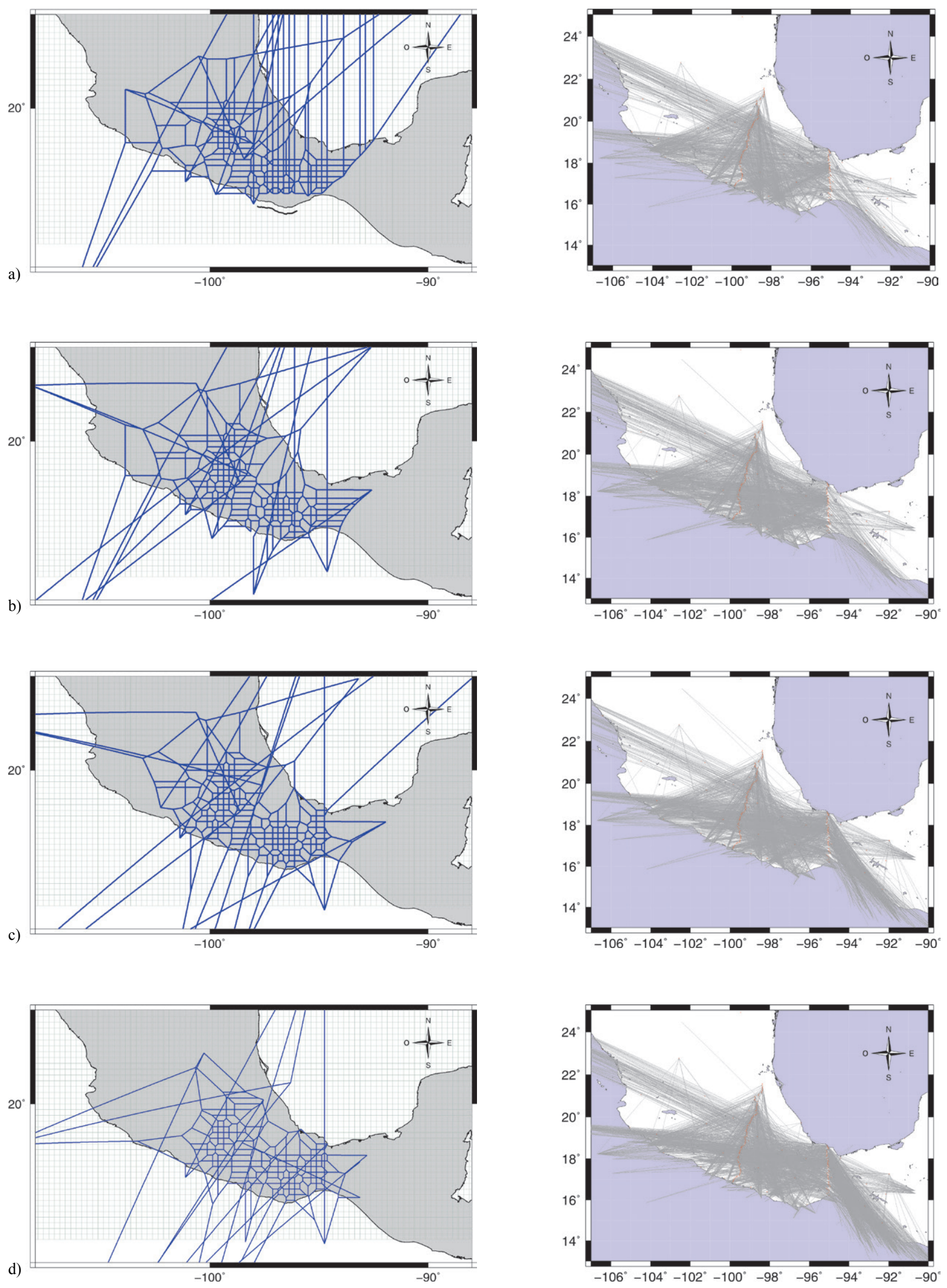

Figura 8. Diagramas de Voronoi y mapas de trayectorias calculados para las pruebas de resolución de los periodos: (a) $\mathrm{T}=10 \mathrm{~s},(\mathrm{~b}) \mathrm{T}=15 \mathrm{~s}$, (c) $\mathrm{T}=20$ $\mathrm{s} y(d) \mathrm{T}=25 \mathrm{~s}$. 
Tabla 2. Valores de velocidad de grupo promedio y número de trayectorias válidas para algunos periodos utilizados en el cálculo de la inversión tomográfica mediante el método de Rawlinson y Sambridge (2005).

\begin{tabular}{ccc}
\hline $\mathbf{T ~}(\mathbf{s})$ & $\mathbf{U}(\mathbf{k m} / \mathbf{s})$ & Trayectorias $(\#)$ \\
\hline 5 & 2.7692 & 909 \\
8 & 2.7929 & 1000 \\
10 & 2.808 & 1002 \\
15 & 2.8108 & 1067 \\
20 & 2.8576 & 1176 \\
25 & 3.002 & 1266 \\
30 & 3.1915 & 1250 \\
35 & 3.3621 & 1141 \\
40 & 3.5034 & 1052 \\
45 & 3.6186 & 931 \\
50 & 3.7298 & 451 \\
\hline
\end{tabular}

nuestras inversiones tomográficas dentro de este intervalo de períodos (y que se extiende hasta $\mathrm{T}=25 \mathrm{~s}$ ), se ubica en la planicie costera del Golfo, en el sureste del estado de Veracruz y en Tabasco (Figura 9). Es sabido que esta zona corresponde a la denominada Cuenca Deltaica de Veracruz, donde el rasgo superficial más distintivo es el CVLT, en el que se encuentran el volcán activo San Martín Tuxtla y el extinto Santa Marta, además de más de doscientos conos de escoria. Este campo volcánico también está caracterizado por una anomalía de Bouguer positiva (Zamora-Camacho, 2007), con un máximo de $130 \mathrm{mGal}$, que cubre todo el campo volcánico y se extiende hacia el Golfo de México (De la Fuente et al., 1994a). La distribución de esta anomalía elongada en dirección N50W coincide con la alineación de los conos de ceniza como se observa en el mapa de anomalía regional de la Figura 12. De acuerdo con Zamora-Camacho (2007) la anomalía magnética presente en la misma región es debida a la alta susceptibilidad magnética de las rocas volcánicas que forman el CLVT.

En un estudio de tomografía sobre la estructura de atenuación de ondas $\mathrm{P}$ y $\mathrm{S}, \mathrm{V}_{\mathrm{P}} / \mathrm{V}_{\mathrm{S}}$ y $\mathrm{V}_{\mathrm{P}} 3 \mathrm{D}$ de la zona de subducción de la placa de Cocos, en el que se utilizaron eventos registrados por los arreglos temporales MASE y VEOX además de estaciones locales, Chen y Clayton (2012) encontraron que la anomalía baja-velocidad/alta atenuación más prominente se localiza en la corteza bajo la Cuenca de Veracruz, cerca del Istmo de Tehuantepec. Esta anomalía también muestra un alto cociente $\left(\mathrm{V}_{\mathrm{P}} / \mathrm{V}_{\mathrm{S}}\right)$. Alternativamente, en estudios magnetotelúricos realizados a lo largo de una línea de aproximadamente $150 \mathrm{~km}$ al oeste del arreglo VEOX, se muestra la existencia de una zona de baja resistividad que también se localiza bajo la Cuenca de Veracruz al oeste del CVLT (Jödicke et al., 2006), cuya profundidad se estima que alcanza $\sim 40 \mathrm{~km}$, que es el mismo rango donde Chen y Clayton (2012) observan alta atenuación, baja- $\mathrm{V}_{\mathrm{P}} \mathrm{y}$ alto $\mathrm{V}_{\mathrm{P}} / \mathrm{V}_{\mathrm{S}}$, y para lo cual argumentan que esta anomalía puede estar relacionada principalmente con la Cuenca de Veracruz en la corteza superior. Si la anomalía se extiende a la corteza inferior, su origen no está bien entendido, y puede asociarse a algún volcanismo extinto en esta compleja región tectónica (Jödicke et al., 2006).

Sin embargo, del CVLT se requiere una explicación que sea congruente con la aparente contradicción representada por la anomalía gravimétrica positiva, que sugiere la presencia de una estructura con una alta densidad y la anomalía de baja velocidad que se muestra en los mapas tomográficos de la región.

Zamora-Camacho et al. (2010) utilizaron funciones receptor para calcular la corteza bajo el CVLT y estimaron que es relativamente delgada: la profundidad del Moho se encuentra aproximadamente entre 28 y $34 \mathrm{~km}$. Los análisis que realizaron sugieren la presencia de una interface "intracorteza" a profundidades entre 10 y $14 \mathrm{~km}$, lo cual según estos autores, podría corresponder al contacto entre la corteza transicional cristalina en la base y la capa sedimentaria encontrada en muchas otras partes del Golfo de México. En el modelo obtenido en el trabajo desarrollado por Gaite (2013), también se obtienen velocidades bajas hasta $12 \mathrm{~km}$ de profundidad en la Cuenca de Veracruz.

A través del uso de funciones receptor, Cruz-Atienza (2000) encontró que el espesor de la capa de sedimentos bajo la estación TUIG (Tuzandepetl, perteneciente al SSN), que también se localiza dentro del área de influencia de esta anomalía de baja velocidad es de aproximadamente $16 \mathrm{~km}$.

Se puede observar que la anomalía gravimétrica residual negativa presente en la región (De la Fuente et al., 1994b), se corresponde con la anomalía que se muestra en los mapas tomográficos. Esto es un indicativo de la presencia de grandes espesores de sedimentos.

Por otra parte, las anomalías de alta velocidad que aparecen en los periodos $\mathrm{T}=5-15 \mathrm{~s}$ están asociadas a las cadenas montañosas correspondientes a la Sierra Madre Oriental, Sierra Madre del Sur y la Sierra Madre de Chiapas. También se observan anomalías de alta velocidad que no tienen relación con cordilleras pero que coinciden en general con las provincias geológicas del Mesozoico y el Paleozoico en la región.

En los periodos intermedios ( 20 a 40 s), se encuentra que su sensibilidad principal obedece al espesor de la corteza y a la velocidad de las ondas de corte en la corteza inferior y en el manto superior. Dentro de este intervalo de periodos, se considera que las anomalías de baja velocidad se relacionan con una corteza gruesa o con alta temperatura, material parcialmente fundido y/o contenido de fluidos.

La anomalía de baja velocidad más pronunciada se observa claramente en el centro y SE de la FVTM a 30 y 40 s. En esta zona se concentra la mayor parte de los estratovolcanes formados en el último millón de años (Ferrari et al., 2012) y donde se obtienen los mayores espesores de corteza de la FTVM ( $\sim 50 \mathrm{~km})$. Los resultados de Iglesias et al. (2010) muestran una zona de baja velocidad bien definida bajo la parte activa de la FVTM (que también 

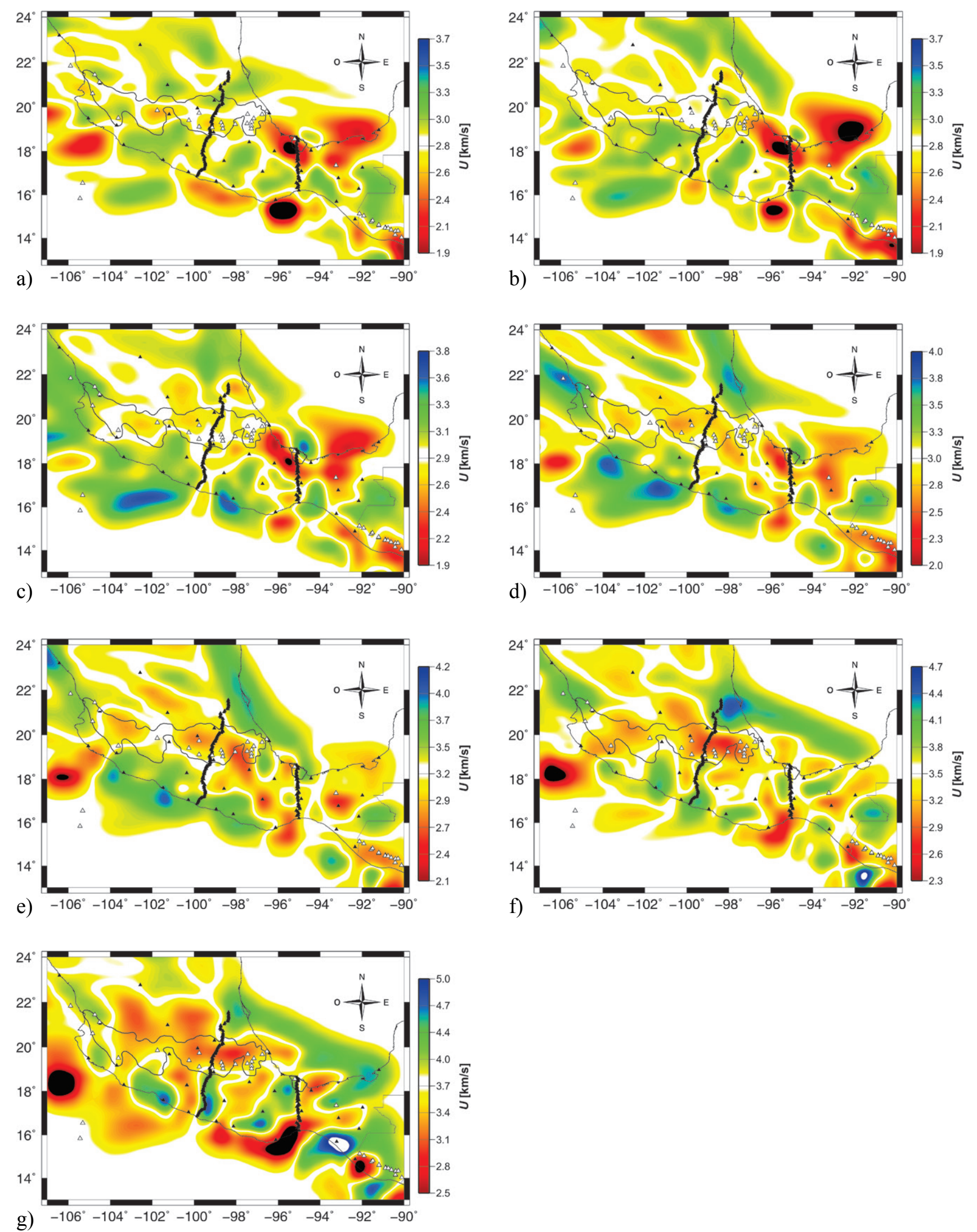

Figura 9. Resultados de la inversión tomográfica de tiempos de viaje utilizando el método Fast Marching Method (FMM) propuesto puesto por Rawlinson y Sambridge (2005) para diferentes periodos, donde la escala de colores en cada mapa tomográfico representa la variación de la velocidad de grupo promedio de las ondas superficiales de Rayleigh. Los mapas tomográficos corresponden a los periodos: a) $\mathrm{T}=10 \mathrm{~s}, \mathrm{~b}) \mathrm{T}=15 \mathrm{~s}, \mathrm{c}) \mathrm{T}=20 \mathrm{~s}, \mathrm{~d}$ ) $\mathrm{T}=25 \mathrm{~s}$, e) $\mathrm{T}=30 \mathrm{~s}, \mathrm{f}) \mathrm{T}=40 \mathrm{~s}$ y $\mathrm{g}$ ) $\mathrm{T}=50 \mathrm{~s}$. 


\section{Desajuste de tiempo de viaje (s)}
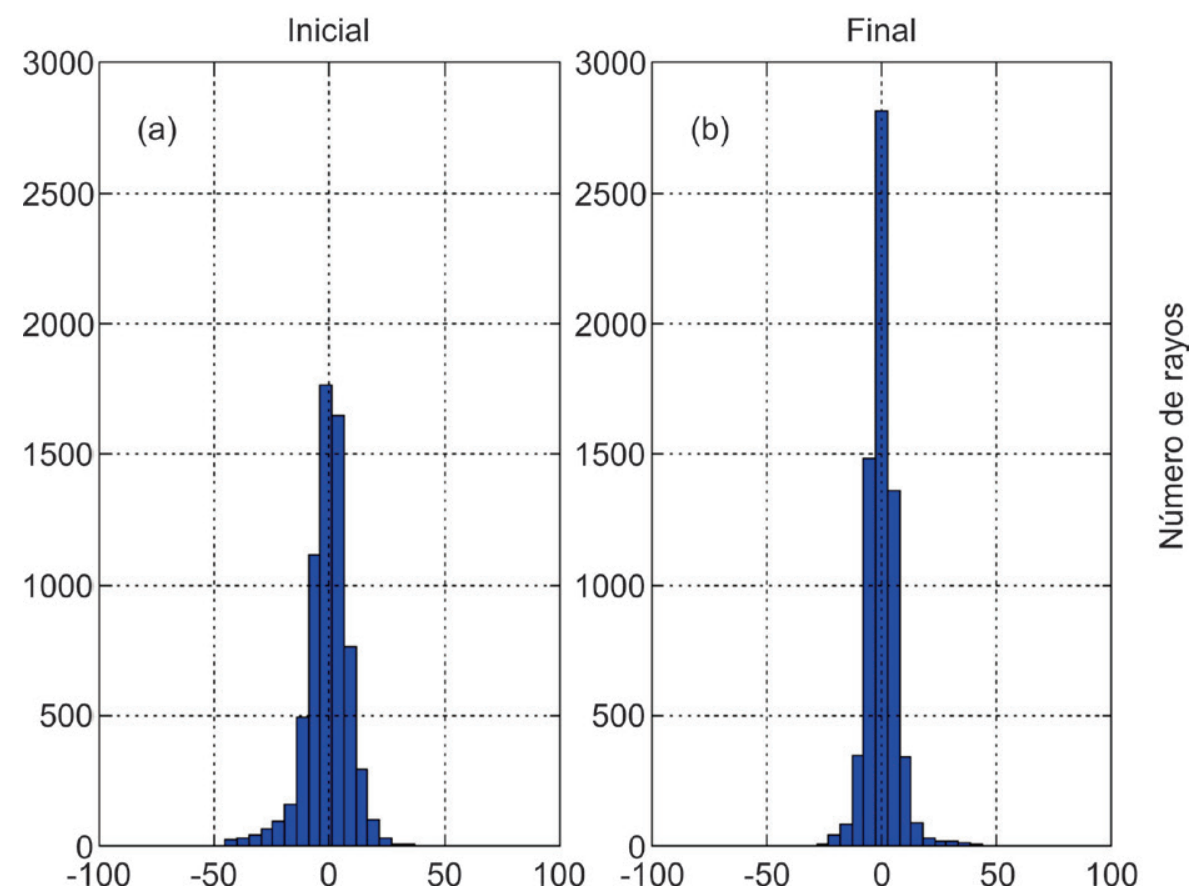

Figura 10. Histogramas de frecuencia que muestran el ajuste entre los datos de tiempo de viaje "observados" de (a) el modelo inicial, y (b) el modelo solución para $\mathrm{T}=30 \mathrm{~s}$.
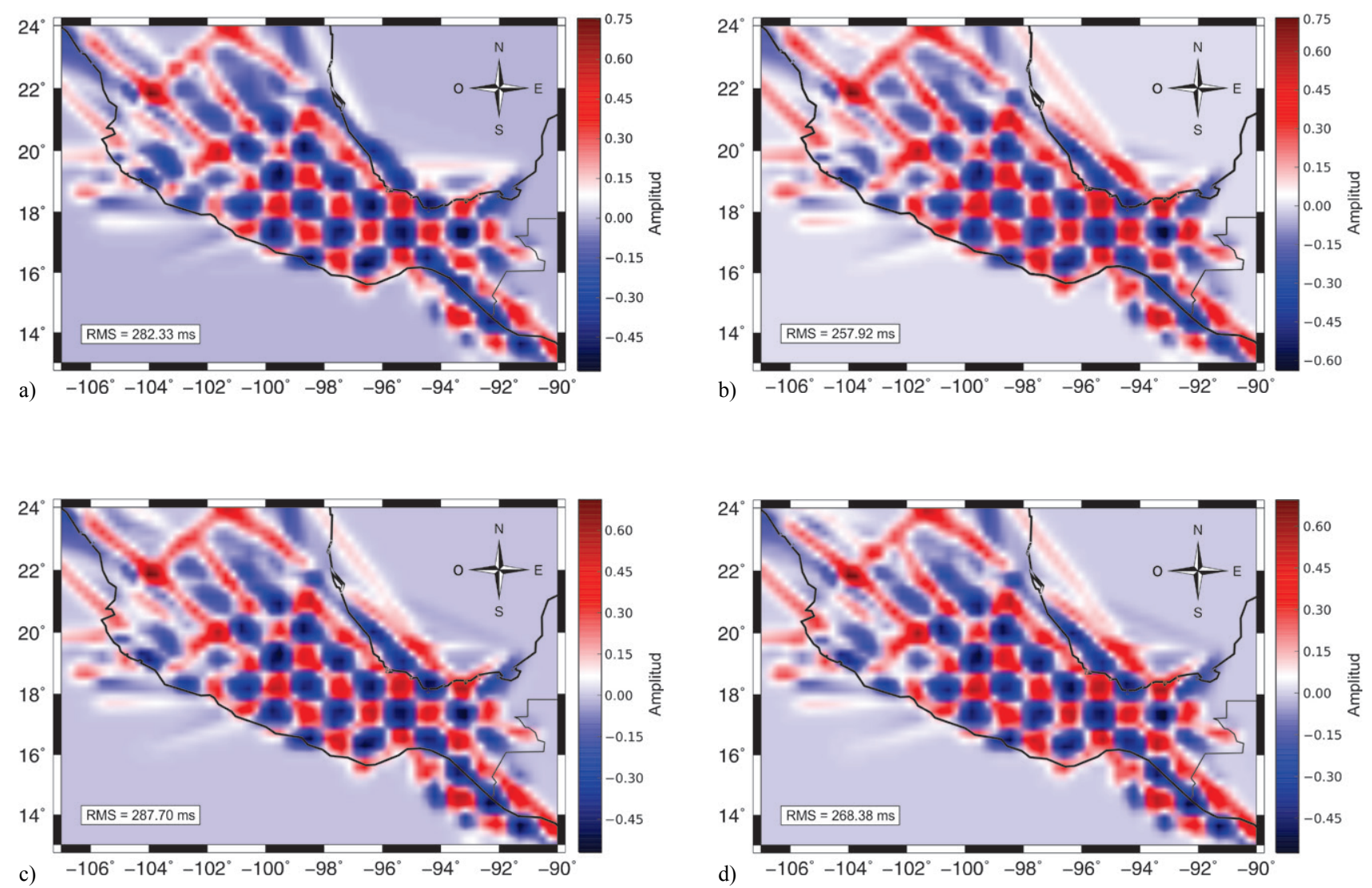

Figura 11. Tableros de ajedrez recuperados para (a) $\mathrm{T}=10 \mathrm{~s}$, (b) $\mathrm{T}=20 \mathrm{~s}$, (c) $\mathrm{T}=30 \mathrm{~s}$ y (d) $\mathrm{T}=40 \mathrm{~s}$. 


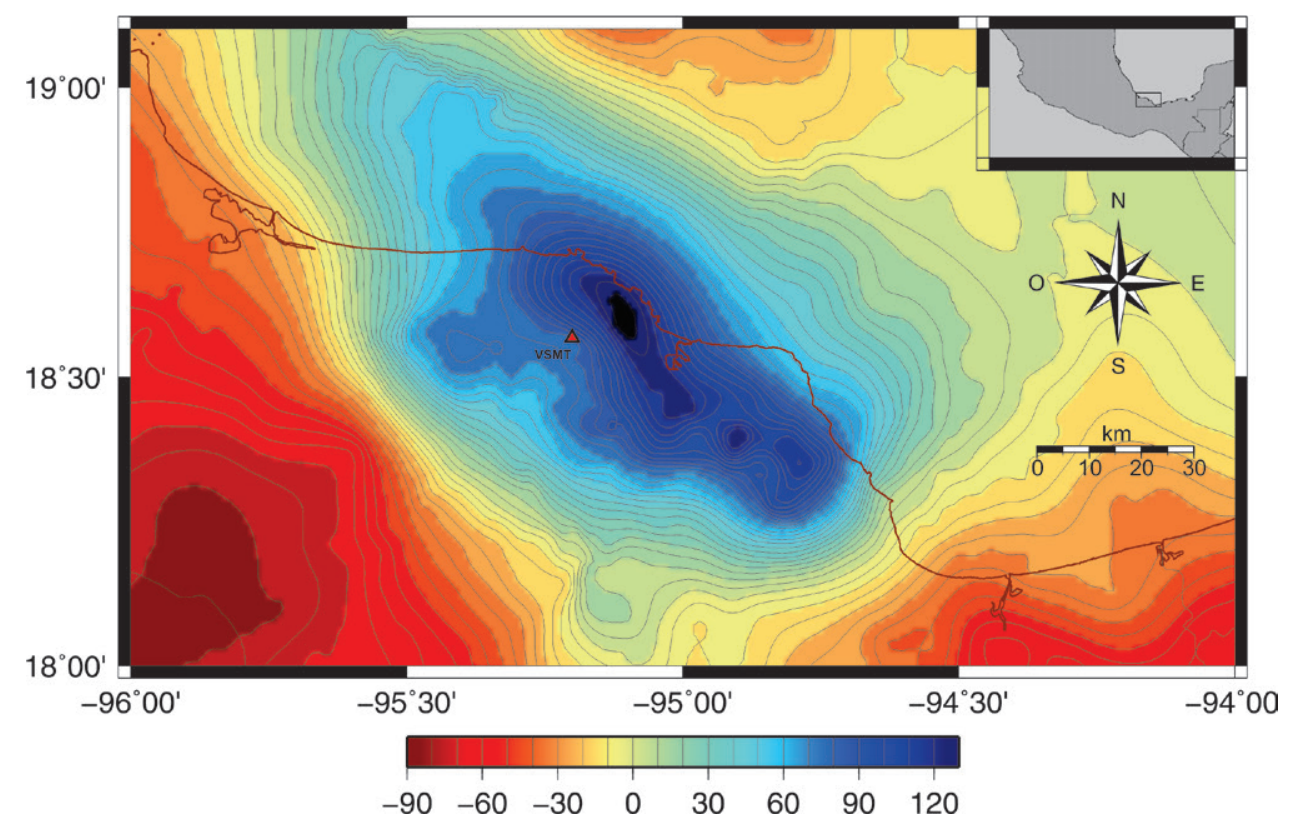

Figura 12. Anomalía gravimétrica presente en el CVLT que se ubica próxima al área donde las inversiones tomográficas calculadas en este estudio identifican una anomalía de baja velocidad de ondas sísmicas. Los contornos están expresados en mGals (Modificada de La Fuente et al., 1994a).

se observa en nuestros mapas tomográficos) que apunta a la presencia de una cuña del manto. Otras anomalías de baja velocidad se distinguen en las zonas volcánicas correspondientes al volcán San Martín en el CLVT, el Chichón en el Arco Volcánico Chiapaneco Moderno (AVCM) y el Arco Volcánico de Centroamérica (AVCA).

En esta misma gama de periodos se observa otra anomalía de baja velocidad que se ubica en la corteza de Oaxaca. De acuerdo con las columnas litológicas y las densidades inferidas para los terrenos tectonoestrátigráficos presentada por Ortega et al. (2008), los terrenos Zapoteco y Plataforma de Morelos (Figura 1) tienen el mayor espesor de corteza en la región sur del país ( $\sim 46 \mathrm{~km})$, y les sigue el Mixteco con una profundidad $>40 \mathrm{~km}$. Esto parece ser congruente con la inversión tomográfica, particularmente en $\mathrm{T}=30 \mathrm{~s}$, donde la distribución de la anomalía de baja velocidad estaría muestreando la corteza gruesa que se describe en el trabajo mencionado.

Las altas velocidades a estos periodos indican una corteza delgada (corteza continental adelgazada o corteza oceánica), que es el caso de las anomalías de alta velocidad que se observan principalmente en las costas de Guerrero y parte de Oaxaca.

En el caso de periodos mayores a los $50 \mathrm{~s}$, las imágenes tomográficas deben ser capaces de mostrar estructura con profundidades mayores a los $50 \mathrm{~km}$. Dado que el rango de frecuencias utilizadas en el presente estudio (5 a 50 s) es relativamente amplio, se considera suficiente para muestrear profundidades que van desde la corteza superior hasta el manto superior. Las características más notables para los periodos largos (>40 s) son las diferencias entre las anomalías de alta velocidad debajo del bloque Maya y el Golfo de México, mientras que las anomalías positivas en el Istmo de Tehuantepec coinciden con la ausencia de volcanismo en esa zona de la trinchera de subducción Mesoamericana.

\section{Conclusiones}

Dentro de los resultados más importantes derivados del presente trabajo, es importante destacar la contribución de la cantidad de registros de eventos y ruido sísmico que permitió contar con los elementos necesarios para obtener una alta resolución en los mapas tomográficos. De igual forma, el uso de dos técnicas diferentes corroboró que las inversiones tomográficas son muy similares entre sí, lo cual da lugar a interpretaciones fidedignas de los resultados obtenidos.

En lo que respecta a la interpretación de la tomografía sísmica, se encontró que mostró una buena correlación con estudios previos enfocados a la caracterización de la corteza terrestre desde distintas perspectivas que comprenden aspectos tectónicos, geológicos y sismológicos. El siguiente paso que deberá desarrollarse será la determinación de modelos de estructura de velocidades a partir de este conjunto de datos, que serán de mucha utilidad principalmente en aquellas zonas donde se carece de ellos, como es el caso de región del Golfo de México.

Finalmente, un aspecto sobre el que es necesario poner atención es el estudio desde diferentes áreas del conocimiento de la zona de sur del estado de Veracruz, donde se ha evidenciado a través de este estudio una tectónica compleja y la presencia de un importante bloque de sedimentos que abarca un área considerable y actualmente cuenta con una infraestructura urbana, industrial y portuaria 
significativa, donde para estas condiciones específicas, no existe una evaluación del peligro asociado.

\section{Agradecimientos}

Agradecemos al Servicio Sismológico Nacional de México (SSN) y al Observatorio de Caltech, particularmente a la Fundación Gordon and Betty Moore por habernos proporcionado los datos de MASE y VEOX utilizados en el presente trabajo, así como al Instituto de Geofísica de la UNAM por las facilidades otorgadas. De igual forma agradecemos a E. Debayle y M. Sambridge por proporcionarnos sus códigos tomográficos y de resolución y a M. Schimmel por facilitarnos su programa para apilado tf-PWS. Este proyecto de investigación fue apoyado por el proyecto CONACYT \#129820, el PROMEP a través de una beca para la realización de estudios Doctorales de Francisco Córdoba Montiel y por la Universidad Veracruzana que le otorgó la respectiva descarga académica.

\section{Referencias}

Andreani, L., Rangin, C., Martínez-Reyes, J., LeRoy, C., Aranda García, M., Le Pichon, X., Peterson-Rodriguez, R., 2008, The Neogene Veracruz fault: evidences for left-lateral slip along the southern Mexico block: Bulletin de la Société géologique de France,179 (2), 195-208.

Baig, A.M., Campillo, M., Brenguier, F., 2009, Denoising seismic noise cross correlations: Journal of Geophysical Research, 114 (B08310), $1-12$.

Bakulin, A., Calvert, R., 2006, The Virtual Source method: theory and case study: Geophysics, 71, SI139-SI150.

Barmin, M.P., Ritzwoller, M.H., Levshin, A.L., 2001, A fast and reliable method for surface wave tomography: Pure and applied Geophysics, $158,1351-1375$.

Bensen, G.D., Ritzwoller, M.H., Barmin, M.P., Levshin, A.L., Lin, F., Moschetti, M.P., Shapiro, N.M., Yang, Y., 2007, Processing seismic ambient noise data to obtain reliable broad-band surface wave dispersion measurements: Geophysical Journal International, 169, 1239-1260

Brenguier, F., Shapiro, N.M., Campillo, M., Ferrazzini, V., Duputel, Z., Coutant, O., Nercessian, A., 2008, Towards forecasting volcanic eruptions using seismic noise: Nature Geoscience, 1, 126-130.

Campa, M.F., Coney, P.J., 1983, Tectono-stratigraphic terranes and mineral resource distributions in Mexico: Canadian Journal of Earth Sciences, 20, 1040-1051

Campillo, M., Singh, S.K., Shapiro, N., Pacheco, J., Hermann, R.B, 1996, Crustal structure of the Mexican volcanic belt, based on group velocity dispersion: Geofísica Internacional, 35(4), 361-370.

Campillo, M., Paul, A., 2003, Long-range correlations in the diffuse seismic coda: Science, 299, 547-549.

Chen, T., Clayton R.W., 2012, Structure of central and southern Mexico from velocity and attenuation tomography: Journal Geophysics Research, 117 (B09302), 1-13.

Cruz-Atienza, V.M., 2000, Inversión global con Algoritmos Genéticos y Cristalización Simulada aplicada a funciones de receptor: modelos estructurales de velocidades para la corteza en la República Mexicana: México, Facultad de Ingeniería, Universidad Nacional Autónoma de México, tesis de licenciatura, $215 \mathrm{p}$.

de Kool, M., Rawlinson, N., Sambridge, M., 2006, A practical grid based method for tracking multiple refraction and reflection phases in 3d heterogeneous media: Geophysical Journal International, 167, 253-270.

De la Fuente M., Mena, M., Aiken, C., 1994a, Cartas Gravimétricas de la República Mexicana, 1 carta de Anomalía de Bouguer, UNAM.

De la Fuente, M., Aiken, C., Mena, M., Simpson R.W., 1994b, Cartas Gravimétricas de la República Mexicana, 3 carta de Anomalía Residual Isostático, UNAM.

Debayle, E., Sambridge, M., 2004, Inversion of massive surface wave data sets: model construction and resolution assessments: Journal of Geophysical Research, 109 (B02316), 1-20.

Derode, A., Larose, E., Tanter, M., de Rosny, J., Tourim, A., Campillo, M., Fink, M., 2003, Recovering the Green's function from field-field correlations in an open scattering medium: Journal of the Acoustical Society of America, 113, 2973-2976.

Duvall, T.L., Jefferies, S.M., Harvey, J.W., Pomerantz, M.A., 1993, Time distance helioseismology, Nature, 362, 430-432.

Dziewonski, A.M., Bloch, S., Landisman, M., 1969, A technique for the analysis of transient seismic signals: Bulletin of the Seismological Society of America, 59, 427-444.

Ferrari, L., Orozco-Esquivel, M.T., Manea, V., Manea, M., 2012, The dynamic history of the Trans-Mexican Volcanic Belt and the Mexico subduction zone: Tectonophysics, 522-523, 122-149.

Fix, J. E., 1975, The crust and upper mantle of central Mexico: Geophysical Journal of the Royal Astronomical Society, 43, 453-500.

Gaite, B., Iglesias, A., Villaseñor, A., Herraiz, M., Pacheco, J.F., 2012, Crustal structure of Mexico and surrounding regions from seismic ambient noise tomography: Geophysical Journal International, 188, 1413-1424.

Gaite-Castrillo, B., 2013, Análisis y aplicaciones del ruido sísmico en México, Golfo de México y Caribe: Tomografía de ondas superficiales Rayleigh y Love: España, Universidad Complutense de Madrid, Tesis Doctoral, 204 p.

Gomberg, J.S., Priestley, K.F., Masters, T.G., Brune, J.N., 1988, The structure of the crust and upper mantle of northern Mexico: Geophysical. Journal International, 94(1), 1-20.

Gómez-Tuena, A., Orozco-Esquivel, T., Ferrari, L., 2005, Petrogénesis ígnea de la Faja Volcánica Transmexicana en Volumen conmemorativo del centenario, temas selectos de la Geología Mexicana: México; Sociedad Geológica Mexicana, LVII, 3, 227-283.

Gudmundsson, O., Sambridge, M., 1998, A regionalized upper mantle (RUM) seismic model: Journal of Geophysical Research, 103, 7121-7136.

Guzmán-Speziale, M., Meneses-Rocha, J.J., 2000, The North AmericaCaribbean plate boundary west of the Motagua-Polochic fault system: a fault jog in southeastern Mexico: Journal of South American Earth Science, 13, 459-468.

Iglesias, A., Cruz-Atienza, V.M., Shapiro, N.M., Singh, S.K., Pacheco, J.F., 2001, Crustal structure of southcentral Mexico estimated from the inversion of surface-wave dispersion curves using genetic and simulated annealing algorithms: Geofísica Internacional, 40, 181-190.

Iglesias, A., Clayton, R.W., Pérez-Campos, X., Singh, S.K., Pacheco, J.F., García, D., Valdés-González, C., 2010, S wave velocity structure below central Mexico using high-resolution surface wave tomography: Journal of Geophysical Research, 115 (B06307), 1-20.

Jödicke, H., Jording, A., Ferrari, L., Arzate, J., Mezger, K., Rüpke, L., 2006, Fluid release from the subducted Cocos plate and partial melting of the crust deduced from magnetotelluric studies in southern Mexico: Implications for the generation of volcanism and subduction dynamics, Journal of Geophysical Research, 111 (B08102), 1-22.

Kim, Y., Clayton, R., Keppie, F., 2011, Evidence of a collision between the Yucatan Block and Mexico in the Miocene, Geophysical Journal International, 187, 989-1000.

Levshin, L., Yanovskaya, T.B., Lander, A.V., Bukchin, B.G., Barmin, M.P., Ratnikova, L.I., Its, E.N., 1989, Recording, identification, and measurement of surface wave parameters, en Keilis-Borok, V.I. (ed.), Seismic Surface Waves in Laterally Inhomogeneous Earth: Dordrecht, Netherlands, Kluwer Acad, 131-182. 
Li, C., van der Hilst, R.D., Engdahl, E.R., Burdick, S., 2008, A new global model for P wave speed variations in Earth's mantle: Geochemistry Geophysics Geosystems, 9(5), 1-21.

Lobkis, O.I., Weaver, R.L., 2001, On the emergence of the Green's function in the correlations of a diffuse field: Journal of the Acoustical Society of America, 110, 3011-3017.

MASE (2007): Meso America Subduction Experiment: Caltech Dataset, doi:10.7909/C3RN35SP

Meneses-Rocha, J.J., 1985, Tectonic evolution of the Strike-slip Fault province of Chiapas, Mexico: Texas, U.S.A., Master's thesis, 315 p.

Montagner, J., 1986, Regional three-dimensional structures using long period surface waves: Annals of Geophysics, 4, 283-294.

Nishida, K., Montagner, J.P., Kawakatsu, H., 2009, Global surface wave tomography using seismic hum: Science, 326, 112.

Ortega-Gutiérrez, F., Sedlock, R.L., Speed, R.C., 1994, Phanerozoic tectonic evolution of Mexico, en Speed, R.C. (ed.), Phanerozoic evolution of North American continent-ocean transitions: Geological Society of America, DNAG Continent-Ocean Transect Series, 265-306.

Ortega-Gutiérrez, F., Elías-Herrera, M., Dávalos-Elizondo, M.G., 2008, On the nature and role of the lower crust in the volcanic front of the Trans-Mexican Volcanic Belt and its fore-arc region, southern and central Mexico: Revista Mexicana de Ciencias Geológicas, 25, 346-364.

Pardo, M., Suárez, G., 1995, Shape of the subducted Rivera and Cocos plates in southern Mexico, seismic and tectonic implications: Journal Geophysical Research, 100, 12357-12373.

Peterson, J., 1993, Observations and modeling of seismic background noise: Open-File Report: Albuquerque, NM., US Geological Survey, 93-322.

Poli, P., Campillo, M., Pedersen, H., LAPNET Working Group, 2012, Body-Wave Imaging of Earth's Mantle Discontinuities from Ambient Seismic Noise: Science, 338, 1063-1065.

Rawlinson, N., Sambridge, M., 2003, Seismic traveltime tomography of the crust and lithosphere: Advances en Geophysics, 46, 81-198.

Rawlinson, N., Sambridge, M., 2004, Wavefront evolution in strongly heterogeneous layered media using the fast marching method: Geophysical Journal International, 156, 631-647

Rawlinson, N., Sambridge, M., 2005, The fast marching method: An effective tool for tomographic imaging and tracking multiple phases in complex layered media: Exploration Geophysics, 36, 341-350.

Rickett, J., Claerbout, J., 1999, Acoustic daylight imaging via spectral factorization: helioseismology and reservoir monitoring: Leading Edge, 18, 957-960.

Rickett, J., Claerbout, J., 2000, Calculation of the acoustic solar impulse response by multi-dimensional spectral factorization: Solar Physics, 92(1-2), 203-210.

Ritzwoller, M., Shapiro, N., Levshin, A., Leahy, G., 2001, Crustal and upper mantle structure beneath Antarctica and surrounding oceans, Journal of Geophysical Research, 106, 30, 645-30, 670.

Roux, P., Sabra, K.G., Kuperman, W.A., Roux, A., 2005, Ambient noise cross correlation in free space: theoretical approach: Journal of the Acoustical Society of America, 117, 97-84.

Sabra, K. G., Gerstoft, P., Roux, P., Kuperman, W.A., Fehler, M., 2005, Surface wave tomography from seismic ambient noise in Southern California: Geophysical Research Letters, 32 (L03310), 1-5.

Sambridge, M., Braun, J., McQueen, H., 1995, Geophysical parametrization and interpolation of irregular data using natural neighbours: Geophysical Journal International, 122, 837-857.

Sambridge, M., Faletič, R., 2003, Adaptive whole earth tomography: Geochemistry Geophysics Geosystems, 4 (3-1022), 1-20.

Schimmel, M., Gallart, J., 2007, Frequency-dependent phase coherence for noise suppression in seismic array data: Jornal of Geophysical Research, 112 (B04303), 1-14.

Schimmel, M., Stutzmann, E., Gallart, J., 2010, Using instantaneous phase coherence for signal extraction from ambient noise data at a local to a global scale: Geophysical Journal International, 184, 494-506.
Schuster, G.T., Yu, J., Sheng, J., Rickett, J., 2004, Interferometric/ daylightseismic imaging: Geophysical Journal International, 157, 838-852.

Sedlock, R., Ortega-Gutiérrez, F., Speed, R., 1993, Tectonostratigraphic terranes and the tectonic evolution of Mexico: Geological Society of America, Special Paper, 278, 153 p.

Sens-Schönfelder, C., Wegler, U., 2006, Passive image interferometry and seasonal variations of seismic velocities at Merapi Volcano, Indonesia: Geophysical Research Letters, 33 (L21302), 1-5.

Shapiro, N.M., Singh, S.K., 1999, A systematic error in estimating surface-wave group-velocity dispersion curves and a procedure for its correction: Bulletin of the Seismological Society of America, $89,1138-1142$.

Shapiro, N.M., Campillo, M., 2004, Emergence of broadband Rayleigh waves from correlations of the ambient noise: Geophysical Research Letters, 31 (L07614), 1-8.

Shapiro, N.M., Campillo, M., Stehly, L., Ritzwoller, M.H., 2005, High resolution surface wave tomography from ambient seismic noise: Science, 307, 1615-1618.

Snieder, R., 2004, Extracting the Green's function from the correlation of coda waves: a derivation based on stationary phase: Physical Review E, 69(4-046610), 1-8.

Snieder, R., Wapenaar, K., Wegler, U., 2007, Unified Green's function retrieval by cross-correlation: connection with energy principles: Physical Review E, 75 (036103), 155-170.

Tarantola, A., Valette, B., 1982, Generalised nonlinear inverse problems solved using the least square criterion: Reviews of Geophysics, 20, 219-232.

Tarantola, A., Nercessian, A., 1984, Three-dimensional inversion without blocks: Geophysical Journal of the Royal Astronomical Society, 76, 299- 306

Valdés, C., Mooney, W.D., Singh, S.K., Meyer, R.P., Lomnitz, C., Luetgert, J.H., Helsley, B.T., Lewis, B.T.R., Mena, M., 1986, Crustal structure of Oaxaca, Mexico from seismic refraction measurements: Bulletin of the Seismological Society of America, 76, 547-564.

Van der Lee, S., Nolet, G., 1997, Seismic image of the subducted trailing fragments of the Farallon Plate: Nature, 386, 266-269.

Vdovin, O., Rial, J.A., Levshin, A., Ritzwoller, M.H., 1999, Group velocity tomography of South America and the surrounding oceans: Geophysical Journal International, 136, 324-340.

VEOX (2010): Veracruz-Oaxaca Subduction Experiment. Caltech. Dataset. doi:10.7909/C3MW2F2C

Wapenaar, K., 2004, Retrieving the elastodynamic Green's function of an arbitrary inhomogeneous medium by cross correlation: Physical Review Letters, 93 (254301), 1-4.

Wapenaar, K., Slob, E., Snieder, R., 2006, Unified Green's function retrieval by cross-correlation: Physical Review Letters, 97 (234301), 1-4.

Wegler, U., Sens-Schönfelder, C., 2007, Fault zone monitoring with passive image interferometry: Geophysical Journal International, $168,1029-1033$

Yang, Y., Ritzwoller, M.H., Levshin, A.L., Shapiro, N.M., 2007, Ambient noise Rayleigh wave tomography across Europe: Geophysical Journal International, 168, 259-274.

Zamora-Camacho, A., 2007, Estudio vulcanológico del área del volcán San Martín Tuxtla, Veracruz, México: México, Universidad Nacional Autónoma de México, Tesis Doctoral, 94 p.

Zamora-Camacho, A., Espíndola, V.H., Pacheco, J. F., Espíndola, J.M., Godínez, M. L., 2010, Crustal thickness at the Tuxtla Volcanic Field, (Veracruz, Mexico) from receiver functions: Physics of the Earth and Planetary Interiors, 182, 1-9.

Manuscrito recibido: Enero 13, 2014.

Manuscrito corregido recibido: Marzo 9, 2014.

Manuscrito aceptado: Marzo 10, 2014. 